\title{
IMPACT OF FIVE PERSONALITY TRAITS ON IMPULSIVE BUYING BEHAVIOR
}

\author{
Shahtaj Waheed Khan ${ }^{1}$
}

\begin{abstract}
This research study attempts to understand the impulsive buying behavior which is defined as "an individual type of buying behavior whereby consumers repetitively spend more than they should base on financial considerations". The study identified that personality traits such as Extraversion, Agreeableness, Conscientiousness, Neuroticism and Openness to experiences are statistically significant variables in affecting impulse purchase. Quantitative approach was implemented, and explanatory designs were used to describe the factors. The study targeted, buyers of different shopping malls in Karachi. From unknown size of buyers, 384 visitors were sampled through non-probability sampling technique. The study data was collected through questionnaire and analyzed by using explanatory methods. The study concluded that the personality traits extraversion, conscientiousness, neuroticism, and openness have the association between impulse buying behavior however, there is no association between agreeableness and impulse buying behavior.
\end{abstract}

Keywords: Consumer Behavior, Impulsive Buying, Extraversion, Agreeableness, Conscientiousness, Neuroticism, Openness.

\section{INTRODUCTION}

An "impulse purchase or impulse buying is an unplanned decision to buy a product or service, made just before a purchase. It is a spontaneous, immediate purchase without pre-shopping intentions either to buy a specific product category or to fulfill a specific buying task (Beatty and Ferrell, 1998). One who tends to make such purchases is referred to as an impulse purchaser or impulse buyer. Impulse buying disrupts the normal decision-making models in consumers' brains.

This study aims to explore the nature and extent of relationship between impulsive buying behavior and personality traits. The entire paper has been divided into 5 chapters. As the

\footnotetext{
${ }^{1}$ Assistant Manager, Data Analyst, Karachi Electric, Pakistan. Email: shahtajkhan1993@gmail.com
} 
introductory and background note forms Chapter 1 deals with statement of problem, justification, and limitations of the study. In subsequent Chapter 2, theoretical framework, and hypotheses formation for the study. Chapter 3 defines the research design, instrumentation, and Data analysis plan. Lastly, Chapter 4 and 5 points out Results and conclusions of the study and discusses scope for related future directions. The purpose of this research was to identify the variables related to impulsive buying and identify the relationship of these variables.

\section{Statement of Problem}

Understanding the different factors about what really drive customers to purchase without planning (since impulse buying occurs when a consumer experiences a sudden, often powerful and persistent urge to buy something immediately (Salih, 2019), marketers can be able to get a sustainable competitive advantage over their competitors. Therefore, marketers need to understand such kind's consumer behaviors in order to formulate the appropriate marketing strategy, allocate marketing budget below-the-line and design effective marketing tactics, (Salih, 2019).

Sellers are mainly focus on quality, product, and prices. While making purchases of products and services there are other factors which should also be considered like personality traits of different types of consumers. This research is to investigate how personality traits are impacting on impulsive buying behavior of consumers by visiting in different shopping malls of Karachi.

\section{RESEARCH QUESTIONS}

Following are the important questions that are linked to the main aim of the study:

Q1. Why consumer purchase such products, they did not plan before purchase?

Q2. Do you think that personality can be used as a tool by retailers for increasing sales?

Q3. Whether any, some or all the personality traits are necessary for displays of impulsive buying behaviors?

\section{SIGNIFICANCE OF STUDY}

The study will be a significant endeavor to its reader to provide an in-depth knowledge regarding the personality traits that affect the impulse buying behavior of the consumers. Also, this report will help the management team in any organization to know about the personality factors that affect the customers' attention towards various products and services evaluated variables are common for all the shopping malls. 


\section{LITERATURE REVIEW}

This section provides in-depth review of literature related to impulse buying: definitions and characteristics of impulse buying and normative evaluations of impulse buying behavior as well as factors and cues influencing impulse buying behavior. In addition, this part of the study outlines the underpinning body of knowledge on which the issue under investigation is based on.

\section{Impulsive buying}

After the sustained love affair of researchers in defining and redefining impulsive buying behavior in earlier studies (Badgaiyan \& Verma, 2014), the focus gradually shifted from the 'what' of impulsive buying to the 'why' and then to the 'how' of it.

Impulse buying of the shopper is influenced by number of factors which could be either related to the shopping environment, shopper's personal traits, product itself and the diverse demographic and socio-cultural aspects. Internal Stimuli are related to the different personality related factors which characterizes an individual rather than the shopping environment or stimuli. Internal factors of impulse buying denote the individual's internal cues and characteristics that make him / her engage in impulse buying. Impulse buying behavior has been observed as one of the remarkable studies conducted by researchers and marketers, as impulse buying has becoming a predominant phenomenon in all retail formats, it is becoming such a part of every person's lifestyle that they do not realize and are not even aware that they are practicing it all the time (Khawaja, 2018).

Impulse buying occurs when a consumer experiences a sudden, often powerful, and persistent urge to buy some-thing immediately. The literature has further pointed out that a productspecific conceptualization of the impulse buying behavior was a better predictor of actual impulse purchasing behavior when compared to general impulse buying tendency. (Jones, Reynolds, Weun, \& Beatty, 2003).

\section{Personality}

Consumer characteristics related to impulsive buying have been a subject of many studies (Badgaiyan \& Verma, 2014), personality is unique and dynamic organization of characteristics of a particular person - physical and psychological - which influences behavior and responses to the social and physical environment. In other words, it is a set of psychological traits and mechanisms within the individual that are organized and relatively enduring (Badgaiyan \& 
Verma, 2014). Also, Herabadi (2003) demonstrated that whilst conscientiousness and agreeableness correlated negatively with the impulsive buying tendency, the cognitive dimension, neuroticism was positively associated with the impulsive buying affective factor. The emergence of five-factor model has enabled researchers to focus on a coreset of behavioral traits extraversion, neuroticism, agreeableness, conscientiousness, and openness to experience.

\section{Personality Traits and Impulse Buying}

\section{Neuroticism and Impulsive buying Behavior}

This trait is associated with the normal personality, which facilitates the tendency of an individual to experience destructive and damaging effects of anxiety, distress, grief, unhappiness, humiliation, embarrassment, antagonism, guiltiness, and antipathy. Individuals scoring high score in this trait might be facing some psychiatric issues, as this trait leads an individual to produce irrational, illogical, and unreasonable ideas, which might end up with negative outcomes.

The first personality trait called neuroticism refers to the tendency to experience negative effect such as sadness and vulnerability (Badgaiyan \& Verma, 2014). According to (Asad Shahjehan, 2012) believe that the individuals scoring high in this trait tend to be highly depressive, conscious about them, very much impulsive and defenseless. There is a positive relation between neuroticism and impulse buying behavior because the anxiety or the emotional distress leads people to make an impulse purchase after which they feel bit relieved and relaxed (Asad Shahjehan, 2012).

Impulsive buying positively correlated with neuroticism (emotional instability) which meant that individuals that experienced emotional instability, anxiety, moodiness, irritability, and sadness were more likely to display impulsive buying behaviors. Considering the emotional nature of impulsive buying (Badgaiyan \& Verma, 2014).

\section{Agreeableness and Impulsive buying Behavior}

The second personality trait, 'agreeableness' deals with motives for maintaining positive relations with others and is considered a tendency to be compassionate and cooperative rather than suspicious and antagonistic towards others. Though there is no concrete evidence to associate impulsive buying behavior with the trait agreeableness, in line with, we go by the assumption that inclination toward disregarding harmful consequences associated with impulsive buying tendency could serves as a ground to believe that high impulsive buying behavior would be linked to low agreeableness (Badgaiyan \& Verma, 2014). 
According to Amayah, 2011 people who score high on the agreeableness scale are friendly, generous, willing to help. Teams with members who scored high on the agreeableness scale were more likely to share knowledge than those whose members had lower scores. Similarly, Amayah, 2011 found that agreeableness was positively related to knowledge sharing. Agreeableness had no influence on the relationship between knowledge sharing and accountability supported by management practices (i.e., situations where employees are held accountable for knowledge sharing and rewarded for it) (Amayah, 2011).

\section{Extraversion and Impulsive buying Behavior}

Individuals high on the trait 'extraversion' have an energetic approach to the social and material world and are social, active and have a tendency to experience positive emotions. This sociability means they are more likely to come in contact with salespeople, and given the risktaking propensity being consistent with the extravert disposition toward excitement-seeking and uncertainty reference, the chances of extraverts indulging in impulsive buying is likely to be more as compared to those low of this trait. Extraversion implied a more impulsive person with lower self-control. (Badgaiyan \& Verma, 2014).

According to Amayah (2011), extraversion has a positive influence on knowledge sharing. Extroverted individuals tend to share knowledge whether or not they would be held accounted and rewarded for it. A possible explanation for this finding may be that there is a relationship between extraversion and need to gain status, which has been identified as a motivating factor for knowledge sharing.

\section{Conscientiousness and Impulsive buying Behavior}

The fourth personality trait 'conscientiousness' describes individual differences in the propensity to be self-controlled, responsible to others, hardworking and goal-directed behavior. Needless to say, individuals scoring highly on this trait are considered methodical, well organized, and dutiful, while those low on this trait are thought to be less focused and more likely to be distracted from tasks. Also, as researchers have reported that conscientiousness was likely to play a major role in planning for future expenses. (Badgaiyan \& Verma, 2014). The individuals, scoring low on this trait, are pretty much careless, do not focus much on their life and the goals to be achieved and can be distracted easily. The individuals scoring high in this trait focus more on their future planning and expenses, which eventually limits them to go for impulse purchases. 


\section{Openness and Impulsive buying Behavior}

Of the five personality traits, openness to experience was the strongest predictor of knowledge sharing. However, in organizations that evaluate employees on knowledge sharing and reward them for it (as compared to organizational contexts where knowledge sharing is simply encouraged but not rewarded), individuals with higher levels of openness were less likely to engage in knowledge sharing behaviors. The authors suggested that this difference with prior research may be due to the fact individuals with high levels of openness tend to seek knowledge, rather than share it. (Amayah, 2011).

Individuals who score low in this trait, are considered to be quite conservative, having a limited mental level and behaviorally conventional. They are quite reserved and do not share their emotions too. Whereas people scoring high in this trait produce new ideas and love entertaining people. They are always ready to experience new things and are quite adventurous. It is expected that open minded people tend to adopt or try out new products.

\section{CONCEPTUAL FRAMEWORK}

The conceptual framework used in this research is modified and improvised as follows:

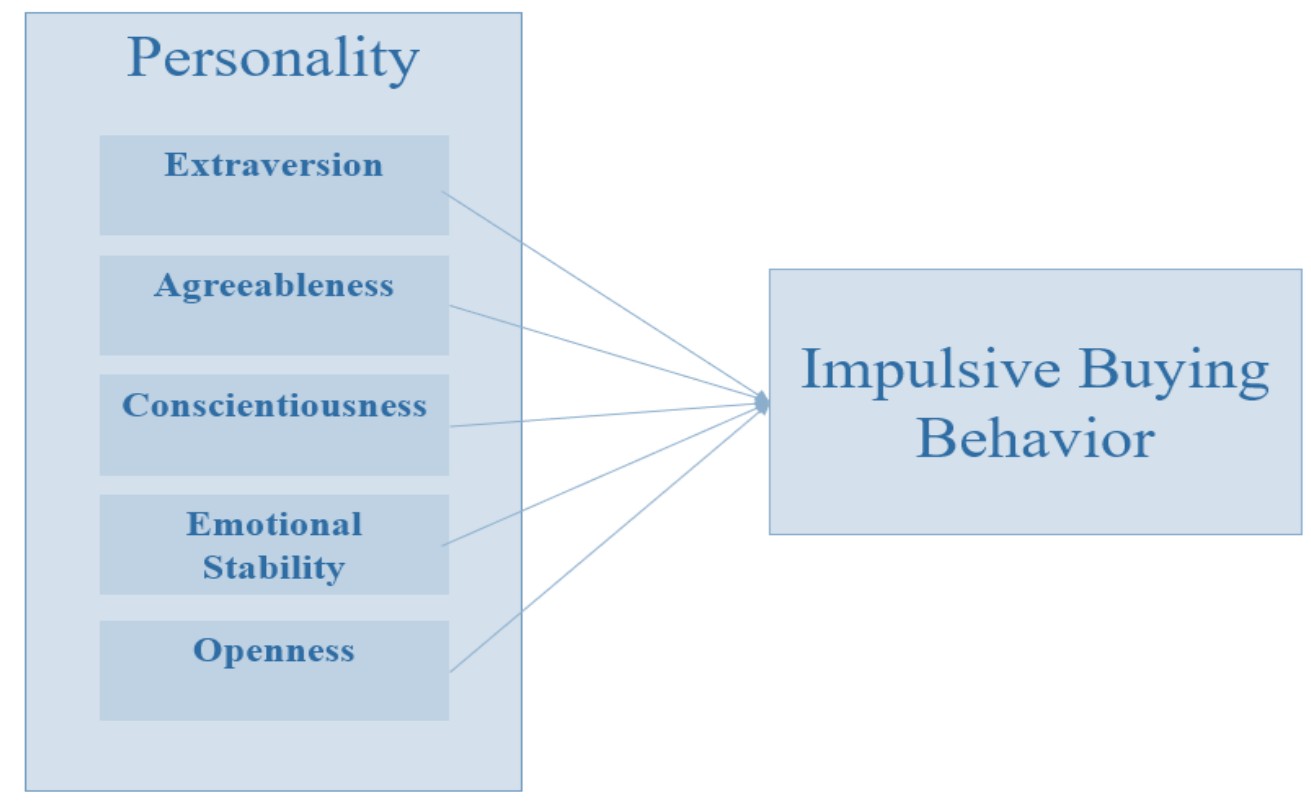

Figure 1. Theoretical Model of Personality Traits affecting impulsive buying behavior

\section{RESEARCH HYPOTHESES}

H1: Extraversion has significant positive effect on impulsive buying behavior.

$\mathrm{H} 2$ : Agreeableness has significant positive effect on impulsive buying behavior. 
H3: Conscientiousness has significant positive effect on impulsive buying behavior.

H4: Neuroticism has significant positive effect on impulsive buying behavior.

H5: Openness has significant positive effect on impulsive buying behavior.

\section{METHODOLOGY}

\section{Research Design}

The research type is Quantitative. This is due to the reason that personality traits effect on impulsive buying behavior of the consumer is identified using quantitative data. Mono research method will be used for this study. This is because of the purpose that already established theory has been tested in different context. The objective of this research is Explanatory as the already established theory is being tested. Based on hypothesis testing this research is basic research because we do not select any specific shopping mall for this research.

\section{Research Technique}

Both primary and secondary data will be collected. Primary data is to be collected through structured questionnaire circulated to individuals visiting different shopping malls. Secondary data will be extracted for information of impulse buying behaviors and personality factors by using the research articles and literature provided online. Moreover, this study has adopted the deductive approach as the already established theory is being tested. In this manner, the hypothesis has been developed at the beginning of the study which have been tested throughout the study.

\section{Population and Sample}

A questionnaire with the topic "Impulsive buying behavior" among consumers of shopping mall in Karachi city. In addition to the survey questionnaire, required data are also collected from several secondary sources like published articles and journals, internet-based articles, and reports. The primary data is processed through Statistical Package Software called SPSS.

\section{Sampling Technique}

The sampling technique used for this research is non-probability convenience sampling technique because subjects are selected as per their convenience accessibility and proximity, so the genuinely interested candidates be approached and requested for furnishing information and their opinions. Also, we have no fixed list about the prospective consumers as to who shall be and when will they be visiting those shopping malls for any purchase, 


\section{Sample Size}

To determine sample size the researchers used the Rao Soft sample size calculated, as the total population of the study in indefinite. Therefore, the sample size of the study was determined to 384 respondents. In five shopping malls and stores, total 384 questionnaires were spread among the customers to collect data while 311 were responded, showing $81 \%$ response rate. Furthermore, the data were collected from 5 different shopping Malls of Karachi.

\section{Instrumentation}

In this research the impact of personality traits on impulse buying behavior was investigated, where Impulse Buying Behavior is a dependent variable and Personality Traits are independent variables. According to Badgaiyan \& Verma, 2014 "personality is a multidimension variable and almost all dimensions of personality should be categorized through big five model (Extraversion, Agreeableness, Conscientiousness, Emotional instability and Openness).

The scale for measuring impulsive buying tendency used in the study had total ten items from which four items measuring the affective component while the other four measuring cognitive part of the trait (Mattila \& Wirtz, 2008), the other two items of impulsive buying were taken from Gupta \& Taushif, 2013, while for measuring the five personality constructs, the total no. of items were twenty-three, Extraversion was analyzed by two items (Badgaiyan \& Verma, 2014), Agreeableness was analyzed by two items (Badgaiyan \& Verma, 2014), Conscientiousness was analyzed by six items (two items taken from Badgaiyan \& Verma, 2014 and the other four were from (Sofi \& Nika, 2016), Neuroticism was analyzed by eleven items (two items taken from Badgaiyan \& Verma, 2014 and the other nine were from (Sofi \& Nika, 2016), whereas, openness to experience analyzed by two items taken from Badgaiyan \& Verma, 2014.

This study has used primary data and it was collected through questionnaire distributed to the individuals who were visiting the shopping malls. The questionnaire was designed by taking the variables out of the theoretical literatures. The questionnaire was prepared using closeended method questions and 5 Point Likert-Scale approaches (i.e., from "Strongly Disagree to Strongly Agree"). For the 5-point Likert scale the respondents were asked to indicate their level of agreement with the ratings of (1) Strongly Disagree, (2) Disagree, (3) Neither Agree nor Disagree, (4) Agree, and (5) Strongly Agree. The researcher visited to shopping malls of different areas and asked buyers in the malls for the willingness to participate in the study. 


\section{Data Analysis}

The data collected from the respondent was analyzed by using quantitative data analysis techniques. Quantitative analysis was used for the data which were collected through structured questionnaire. The descriptive methods were used for primary data such as frequencies, mean and median were used for demographic characteristics of consumers (gender, age, income, and marital status). Since all independent and dependent variables are qualitative in nature so Chisquare test was used to investigate the association between independent variables (Extraversion, Agreeableness, Conscientiousness, Neuroticism, Openness) and dependent variable" (impulse buying behavior).

\section{RESULTS}

\section{Descriptive Statistics}

\begin{tabular}{|c|c|c|c|}
\hline \multicolumn{2}{|l|}{ Grouping } & Frequency & $\%$ \\
\hline \multirow[t]{2}{*}{ Gender } & Male & 148 & $48 \%$ \\
\hline & Female & 163 & $52 \%$ \\
\hline \multirow[t]{5}{*}{ Age } & Less than 20 years & 56 & $18 \%$ \\
\hline & Between 20 and 30 years & 106 & $34 \%$ \\
\hline & Between 30 and 40 years & 95 & $31 \%$ \\
\hline & Between 40 and 50 years & 41 & $13 \%$ \\
\hline & More than 50 years & 13 & $4 \%$ \\
\hline \multirow{3}{*}{ Marital status } & Single & 158 & $51 \%$ \\
\hline & Married & 151 & $49 \%$ \\
\hline & Separated & 2 & $1 \%$ \\
\hline \multirow{2}{*}{$\begin{array}{l}\text { Employment } \\
\text { Status }\end{array}$} & Employed & 176 & $57 \%$ \\
\hline & Unemployed & 135 & $43 \%$ \\
\hline \multirow[t]{6}{*}{ Income level } & Less than Rs. 30,000 & 81 & $26 \%$ \\
\hline & Between Rs. 30,000 and 45,000 & 38 & $12 \%$ \\
\hline & Between Rs. 45,000 and 60,000 & 43 & $14 \%$ \\
\hline & Between Rs. 60,000 and 75,000 & 52 & $17 \%$ \\
\hline & Between Rs. 75,000 and 100,000 & 68 & $22 \%$ \\
\hline & Above Rs. 100,000 & 29 & $9 \%$ \\
\hline
\end{tabular}

Table 1. Sample Profile of Respondents

The demographic information of respondents has been mentioned in Table 1. Out of 384 respondents, $48 \%$ of them were males, whereas $52 \%$ of them were females, which means that the majority of the respondents were females.

In the case of age, the majority (34\%) of them were from the age bracket of 20-30 years, 31\% of them were from the 30-40 age group, $18 \%$ of the respondents were from less than 20 age bracket, $13 \%$ were between 40 and 50 age group and the remaining $4 \%$ of them were from the 
age group of more than 50 years. Therefore, the majority of the respondents were the young individuals.

Analyzing the marital status of the respondents, the majority (51\%) of the respondents were unmarried, $49 \%$ of them were married and $1 \%$ of the respondents were separated. In case of employment, most of the respondents (57\%) were employed, $43 \%$ of them were unemployed. In terms of income level, the majority (26\%) of the respondents had an income of less than $30,000,22 \%$ of respondents were between 75,000 and 100,000 of income level, $17 \%$ had an income between 60,000 and 75,000,14\% of the respondents had an income between 45,000 and $60,000,12 \%$ of the respondents had an income between 30,000 and 45,000, and the remaining of the respondents had an income above Rs. 100,000.

\section{Inferential Statistics}

All independent variables have a significant impact on impulse buying while agreeableness has an insignificant impact on impulse buying.

\section{H1: Openness has positive impact on impulse buying.}

The number of items in openness were two. Since the significance value is less than 0.05 , hence we fail to reject the null hypothesis and conclude that there is an association between Openness and impulse buying.

\section{H2: Conscientiousness has positive impact on an impulsive buying behavior.}

The number of items in conscientiousness were six. The significance value of the analysis is less than 0.05, we accept alternate hypothesis that there is an association between conscientiousness and impulse buying. This trait involves individuals who are focused, goals oriented and always work according to the plan in order to achieve their target. Therefore, the individuals who score low in this trait tend to be more impulsive as compared to the people who score high.

\section{H3: Extraversion has positive effect on an impulsive buying behavior.}

The number of items in extraversion were two. The significance value less than 0.05 validates the alternate hypothesis that there is an association between extraversion and impulse buying. People having this trait are energetic, enthusiastic, and love to socialize and meet new people. They are excited and take life very easily. Therefore, individuals scoring high in this trait tend to be more impulsive.

H4: Agreeableness has positive effect on impulsive buying behavior. 
The number of items in the variable agreeableness were two. The significance value higher than 0.05 rejects the alternative hypothesis stating a positive effect of agreeableness on impulse buying, thus accepting the null hypothesis.

\section{H5: Neuroticism has positive effect on impulsive buying behavior}

The number of items in Neuroticism were eleven and the significance value of less than 0.05 , corroborate the association between neuroticism and impulse buying, hence accepting the alternate hypothesis.

\section{Hypothesis Assessment Summary}

\begin{tabular}{|lll|}
\hline & Hypothesis & Result \\
\hline 1. & Openness has positive impact on impulse buying & Accepted \\
2. & Conscientiousness has positive impact on an impulsive buying behavior & Accepted \\
3. & Extraversion has positive effect on an impulsive buying behavior & Accepted \\
4. & Agreeableness has positive effect on impulsive buying behavior & Rejected \\
5. & Neuroticism has positive effect on impulsive buying behavior & Accepted \\
\hline
\end{tabular}

\section{DISCUSSION}

The results "re-confirm the positive association between impulsive buying and extraversion. This means that outgoing and sociable people were more susceptible to impulsive buying and could be targeted by the salespeople. Thus, based on this finding, on one hand, marketers in general, and retailers in particular, should look for specific indicators to identify people high on extraversion so as to instigate impulsive behavior, while on the other hand, people high on this trait should be more careful so as avoid the possibility of post-purchase dissonance. It has also been supported by literature too, Badgaiyan \& Verma (2014) concluded that the individuals who tend to score high in this personality trait, have positivity in themselves, which makes them more open to everything, and this positivity leads them to engage in impulse shopping; as they have a craze to explore new things which eventually lowers their self-control leading them into shopping impulsively.

According to the study there is a positive association between impulsive buying and conscientiousness. This trait involves individuals who are focused, goals oriented and always work according to the plan in order to achieve their target. Therefore, the individuals who score low in this trait tend to be more impulsive as compared to the people who score high. The result 
of this study is contradictory to the findings of earlier studies (Herabadi, 2003). The results of earlier studies have not been validated in this research. This result has initiated the need to revisit the relationship between these two concepts.

The study of (Badgaiyan \& Verma, 2014) also didn't find the association between impulse buying and agreeableness, nor significant support for this hypothesis. This trait involves individuals who are focused, goal- oriented and work harder to achieve their targets. They are intelligent enough that they do not prefer making decisions on the spot without considering the pros and cons in detail. The result of this study did not support the stance of Herabadi (2003) which posit that the people scoring high in this trait are sensible enough to make proper decisions and are less likely to indulge into impulse buying impulsively.

The result of neuroticism and impulse buying contradictory to the result of (Badgaiyan \& Verma, 2014). This personality trait includes individuals who are highly depressed and stressed out and face negative and destructive feelings. This trait is opposite of the emotional stability. The individuals, who score high in this trait, are not emotionally or mentally stable, which pushes them to shop impulsively to feel better. Usually, anxiety and emotional breakdown also lead an individual to buy things impulsively. The findings of this study support the findings of Asad Shahjehan, 2012 that identified that the individuals who are highly depressed tend to make purchases impulsively.

This result we find out this study of openness and impulse buying is contradictory to the finding of Badgaiyan \& Verma (2014) where this hypothesis was rejected. The influence of openness in leading an individual towards impulse shopping. This trait is opposite to the conservativeness. The people who score high in this trait seem to be quite impulsive and are more likely to make impulse purchases as they are creative, open and try to experience new things as compared to the people who tend to score low in this personality trait.

These significant associations between personality constructs and impulsive buying behavior further strengthen the optimism that impulsive buying could strongly be rooted in personality.

\section{CONCLUSION}

Considering the study of behavior of individuals in shopping malls of Karachi, we studied several similar searches of the impulse buying behavior of people and what are their behavior towards the products displayed in shopping malls of Karachi. We randomly select 5 shopping malls of Karachi due to short of time and we surveyed them one by one on each day. 
First of all, the framework proposes the inclusion of different personality constructs such as extraversion, agreeableness, conscientiousness, neuroticism, and openness in assessing impulsive buying behavior. On the other hand, the obvious contribution of this study is made through validating the efforts of past research efforts of relevant studies in this field through the empirical results. The main objective of this research study was to investigate the role of personality trait namely openness, conscientiousness, extraversion, agreeableness, and neuroticism in leading an individual to engage in an impulsive buying behavior. From the data that has been collected from the target audience, it has been analyzed that openness, extraversion, conscientiousness, and neuroticism play an important role in encouraging an individual to shop impulsively. The individuals, scoring high in these traits, tend to buy things immediately, right on the spot whereas, and agreeableness is negatively associated with the impulsive buying behavior. This study contributes to the deeper understanding of Pakistani consumers specifically on the shopping malls.

Lastly, findings from the study could provide important insight about impulsive buying behavior of Pakistani consumers in high-end shopping malls in relation to the built-in traits and could be utilized equally by both marketers as well as retailers. While the marketers, can strategize to optimally utilize the positive relationship between the constructs such as extraversion, conscientiousness, neuroticism, and openness; it could also be pivotal for future research in the area especially in Pakistani context.

\section{RECOMMENDATIONS FOR FUTURE RESEARCH}

This study has several limitations that need to highlight. The sample size was relatively small (384), and data collection took place in 5 shopping malls of Karachi. Thus, future research with a bigger sample, and tested in other cities and countries, is needed to enhance the generalizability of our findings. Moreover, the study context included the high-end shopping malls, and its consumers must be highly specific. Future work focusing on a different type of shopping malls (high-end and local), supermarkets and retail outlets of street sides to analyze the buying behavior of consumers, it might provide additional insight into the role of personality traits in influencing impulse buying. Also, the impulsive buying habits of consumers from different countries would identify relevant similarities and differences that exist between personalities. This is important in its own respect since consumers from diverse countries/cities/areas hold different personalities and have different consumption patterns that are very likely to have an effect on impulse buying behavior. 
This study evaluates the factors which were associated with personality factors such as extraversion, agreeableness, conscientiousness, neuroticism, and openness. Hence, the proponent recommends to future researchers to deliberate other several factors constituting influence on impulse buying of the consumers. 


\section{REFERENCES}

Amayah, A. T. (2011, September). Knowledge sharing, personality traits and diversity: a literature review. In Proceedings from The Midwest Research-to Practice Conference in Adult, Continuing, and Community Education. St. Louis, MO: USA.

Badgaiyan, A. J., \& Verma, A. (2014). Intrinsic factors affecting impulsive buying behaviourEvidence from India. Journal of Retailing and consumer services, 21(4), 537-549.

Beatty, S. E., \& Ferrell, M. E. (1998). Impulse buying: Modeling its precursors. Journal of retailing, 74(2), 169-191.

Herabadi, A. G. (2003). Buying impulses: A study on impulsive consumption.

Jones, M. A., Reynolds, K. E., Weun, S., \& Beatty, S. E. (2003). The product-specific nature of impulse buying tendency. Journal of business research, 56(7), 505-511.

Khawaja, L. (2018). Factors influencing Consumer Behavior toward Impulse Buying, The International Journal of Business \& Management. Retrieved from https://www.researchgate.net/publication/329013866

Mattila, A. S., \& Wirtz, J. (2008). The role of store environmental stimulation and social factors on impulse purchasing. Journal of services marketing.

Raosoft, Sample size calculator. Retrieved from http://www.raosoft.com/samplesize.html, 2004.

Salih, N. (2019). Determinants of Impulsive Buying Behavior in Some Selected Boutiques of Addis Ababa.

Shahjehan, A., Zeb, F., \& Saifullah, K. (2012). The effect of personality on impulsive and compulsive buying behaviors. African Journal of Business Management, 6(6), 21872194.

Sofi, S. A., \& Nika, F. A. (2016). The role of personality in impulse buying behavior. Jindal Journal of Business Research, 5(1), 26-50.

Taushif, M., \& Gupta, M. (2013). A study of factors affecting impulse buying behaviour of consumers at Malls (Delhi). International Journal of Research and Development-A Management Review, 2(2), 2319-5479. 
Journal of Marketing Strategies, Volume 1, Issue 1, 2019

Van Thiel, D. E. (2018). What are the Big Five Personality Test Traits? Learn all about the Theory. Retrieved from https://www.123test.com/big-five-personality-theory/ 